\title{
Ultrasmall superparamagnetic particles of iron oxide-enhanced magnetic resonance imaging in the assessment of cellular inflammation after myocardial infarction
}

\author{
Colin G Stirrat ${ }^{2,1^{*}}$, Shirjel Alam²,1, Thomas J MacGillivray ${ }^{1,3}$, Calum D Gray ${ }^{1,3}$, Marc R Dweck ${ }^{2,1}$, Saeed Mirsadraee ${ }^{1,4}$, \\ Graham McKillop ${ }^{4}$, Peter A Henriksen ${ }^{2,1}$, David Newby ${ }^{2,1}$, Scott Semple ${ }^{1,2}$
}

From 18th Annual SCMR Scientific Sessions

Nice, France. 4-7 February 2015

\section{Background}

Excessive inflammation after myocardial infarction (MI) can be detrimental to the recovery of cardiac function. ${ }^{1,2}$ Ultrasmall superparamagnetic particles of iron oxide (USPIO)-enhanced magnetic resonance imaging (MRI) can be used to detect myocardial cellular inflammation. USPIO are engulfed by resident macrophages through phagocytosis and pinocytosis resulting in concentration within inflamed tissues. We aimed to determine the time course and duration of USPIO-enhancement following acute MI (Figure 1).

\section{Methods}

Thirty patients with acute MI were studied in the 3-month period following acute MI. Repeated T2*-weighted $3 \mathrm{~T}$
MRI was performed immediately before and $24 \mathrm{~h}$ after USPIO (ferumoxytol, $4 \mathrm{mg} / \mathrm{kg}$ ) administration at $2 \pm 1,5 \pm 2$, $13 \pm 3,21 \pm 4$ and $90 \pm 9$ days. Myocardial regions of interest (ROIs) were drawn and categorised into infarct and noninfarct regions by the presence or absence of late gadolinium enhancement (LGE). R2* values $(1 / \mathrm{T} 2 *)$ within ROIs were determined to assess the time course and duration of uptake of USPIO.

\section{Results}

Following single-dose USPIO administration 2-7 days after acute MI, USPIO uptake is demonstrable at $24 \mathrm{~h}(\mathrm{p}<0.001)$ and is cleared within 4-8 days. Increased USPIO uptake is seen in the infarct region at days $2-3(\mathrm{p}<0.001)$, days 4-7 $(\mathrm{p}<0.01)$, and days 10-16 $(\mathrm{p}<0.05)$ compared to non-
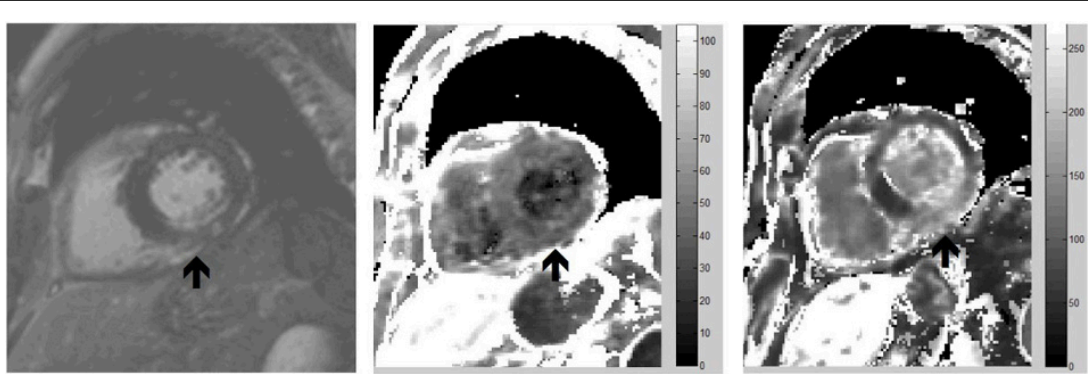

Figure 1 Patient imaged 5 days after an inferior MI. Images show late gadolinium enhancement in the region of the MI (left). R2* colour maps of the baseline pre-USPIO scan (middle), and 24 hours following USPIO administration (right). USPIO uptake, with increased R2* values, is shown by the lighter area of the colour map in the region of the inferior wall infarct (arrow).

${ }^{2}$ Centre for Cardiovascular Science, University of Edinburgh, Edinburgh, UK Full list of author information is available at the end of the article 


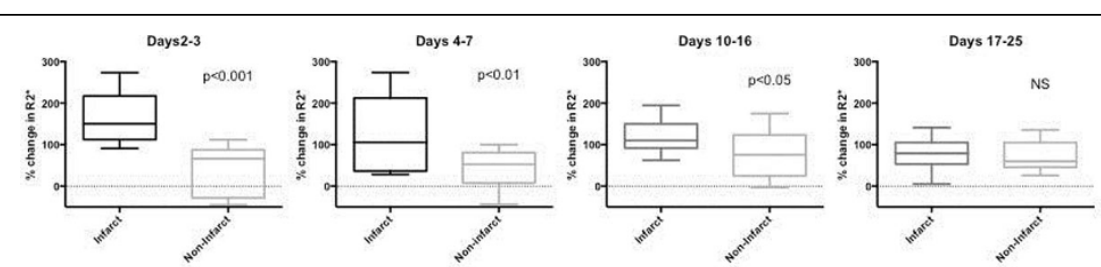

Figure 2 Increased USPIO uptake is seen in the infarct region at days 2-3 ( $p<0.001$ ), 4-7 ( $p<0.01$ ), and days 10-16 ( $p<0.05$ ) compared to noninfarcted myocardium. There is no difference in uptake at later time points (Days 81-99 not shown).

infarcted myocardium (Figure 2). There was no difference in uptake between regions at later time points $(21 \pm 4$ and $90 \pm 9$ days).

\section{Conclusions}

USPIO-enhanced MRI can detect and quantify infarctrelated cellular inflammation in the first 2 weeks following acute MI. This imaging tool holds promise to non-invasively assess myocardial cellular inflammation after MI and in other inflammatory cardiac conditions. It has the potential to monitor disease progression and remission, and may provide a future platform on which to test novel anti-inflammatory therapies for the heart.

\section{Funding}

The BHF have provided funding for this work (FS/12/ 83/29781).

\section{Authors' details}

${ }^{1}$ Clinical Research Imaging Centre, University of Edinburgh, Edinburgh, UK. ${ }^{2}$ Centre for Cardiovascular Science, University of Edinburgh, Edinburgh, UK.

${ }^{3}$ Wellcome Trust Clinical Research Facility, NHS Lothian, Edinburgh, UK.

${ }^{4}$ Department of Radiology, NHS Lothian, Edinburgh, UK.

Published: 3 February 2015

Cite this article as: Stirrat et al.: Ultrasmall superparamagnetic particles of iron oxide-enhanced magnetic resonance imaging in the assessment of cellular inflammation after myocardial infarction. Journal of

Cardiovascular Magnetic Resonance 2015 17(Suppl 1):P252.

Submit your next manuscript to BioMed Central and take full advantage of:

- Convenient online submission

- Thorough peer review

- No space constraints or color figure charges

- Immediate publication on acceptance

- Inclusion in PubMed, CAS, Scopus and Google Scholar

- Research which is freely available for redistribution

Submit your manuscript at www.biomedcentral.com/submit 